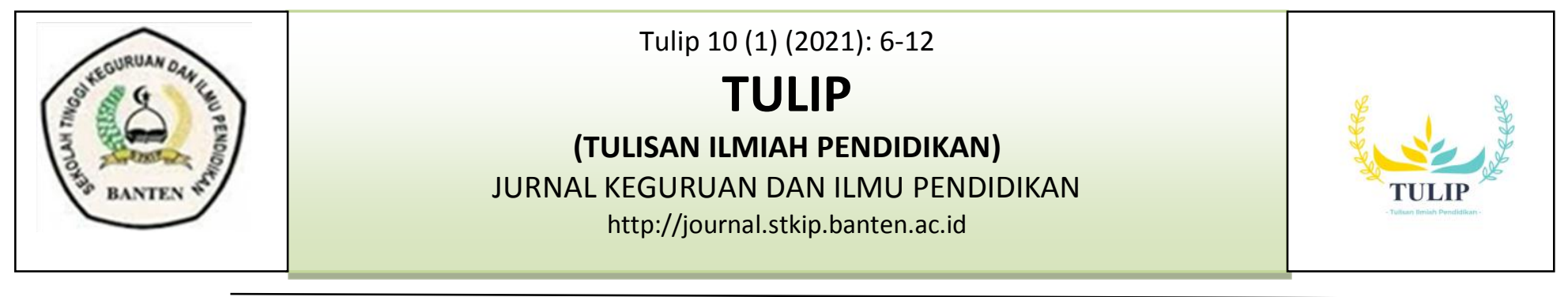

\title{
PENGARUH PERMAINAN TRADISIONAL BEBENTENGAN TERHADAP PEMBELAJARAN ATLETIK SPRINT
}

\author{
Ahmad Yanuar Syauki \\ Sekolah Tinggi Keguruan dan Ilmu Pendidikan Banten \\ aysyauki@yahoo.com \\ Artikel Atletik Sprint \\ Penerima: Desember, 2020 \\ Diterima: Januari, 2021 \\ Dipublikasikan: Maret, 2021

\begin{abstract}
Abstrak
Tujuan penelitian ini adalah untuk mengetahui pengaruh permainan tradisional bebentengan terhadap pembelajaran atletik sprint. Metode penelitian yang digunakan adalah penelitian studi literatur yang terdiri dari beberapa sumber seperti sumber primer dan sumber sekunder. Berdasarkan hasil penelitian yang telah dilakukan peneliti berupa analisa sumber-sumber yang relevan berupa jurnal maupun buku, maka peneliti menemukan bahwa permainan tradisional bebentengan dapat meningkatkan pemebelajaran atletik sprint. Pernyataan ini didukung oleh berbagai penelitian terdahulu yang memperoleh peningkatan pembelajaran atletik sprint ketika menerapkan permainan tradisional bebentengan dalam kegiatan pembelajaran didapatkan bahwa permainan tradisional bebentengan dapat meningkatkan pembelajaran atletik sprint.
\end{abstract}

Kata kunci: Permainan tradisional, bebentengan, Sprint

\section{PENDAHULUAN}

Pendidikan jasmani olahraga dan kesehatan (penjasorkes) merupakan salah satu mata pelajaran yang harus diajarkan di sekolah. Mata pelajaran ini mengembangkan tiga domain pembelajaran yang meliputi: afektif, kognitif, dan psikomotor pada anak yang pelaksanaannya dapat bersifat teoretis maupun aktifitas praktis. Pendidikan jasmani, olahraga dan kesehatan berusaha mencapai tujuan pendidikan melalui aktivitas jasmani. Aktivitas jasmani yang diajarkan meliputi: atletik, senam, renang, olahraga permainan dan aktivitas pengembangan.

Atletik merupakan cabang olahraga yang paling tua usianya di dunia dibandingkan dengan cabang olahraga lainnya. Ditinjau dari aspek geraknya, gerakan yang terdapat dalam cabang 
olahraga atletik merupakan gerakan dasar yang dilakukan manusia, seperti berjalan, berlari, melompat dan melempar. Seiring dengan bertambahnya kemapuan dan perubahan kebudayaan manusia, gerakangerakan tersebut berubah menjadi suatu kegiatan atau aktivitas yang dilombakan atau digunakan untuk meningkatkan kesegaran jasmani atletik mempunyai cabang olahraga yang banyak, terdiri dari 4 nomor yaitu; jalan, lari , lempar dan lompat. Dari sekian banyak nomor-nomor yang ada pada cabang olahraga atletik, penulis berminat untuk membahas nomor lari jarak pendek atau sprint. Dimana lari jarak pendek adalah lari yang menempuh jarak antara 50 meter sampai dengan jarak 400 meter. Oleh karena itu kebutuhan utama untuk lari jarak pendek adalah kecepatan.

Bebentengan merupakan salah satu jenis olahraga tradisional yang dilakukan oleh dua regu. Setiap regu terdiri dari 4-8 orang. Setiap regu akan memilih suatu tempat sebagai markas biasanya berupa tiang, batu maupun pilar rumah sebagai benteng (Ajun khamdani, 2010:15)

Dari pendapat tersebut dapat diartikan bahwa pendekatan permainan bebentengan dapat digunakan sebagai suatu alternatif dalam pembelajaran pendidikan jasmani olahraga dan kesehatan.

Dimana dengan melakukan permainan bebentengan, secara tidak langsung dapat melatih kondisi fisik yang dibutuhkan untuk meningkatkan kecepatan berlari.

Atas dasar hal tersebut, peneliti memandang penting untuk melakukan penelitian yang akan membahas permasalahan mengenai "Pengaruh Permainan Tradisional Bebentengan Terhadap Pembelajaran Atletik Sprint"

\section{Deskripsi Teoritik}

Atletik merupakan salah satu materi pelajaran dalam pendidikan jasmani, olahraga dan kesehatan yang terdiri dari nomor lari, lempar, lompat, dan jalan.(Yoyo Bahagia 2010)

Atletik merupakan aktivitas jasmani yang efektif untuk mengoptimalkan pertumbuhan dan perkembangan anak.(Pandu 2018)

Atletik juga merupakan sarana untuk pendidikan jasmani dalam upaya meningkatkan kemampuan biomorik, mislnya kekuatuan, daya tahan, kecepatan, kelentukan, koordinasi, dan sebagainya. Selain itu juga sebagai sarana untuk pendidikan

Berdasarkan teori-teori yang dijelaskan diatas dapat disimpulkan bahwa atletik adalah suatu cabang olahraga yang didalam nya terdapat gerakan jalan, lari, lompat dan lempar yang dipertandingkan dan efektif juga untuk pertumbuhan serta perkembangan anak.

Lari cepat disebut juga lari sprint yang menempuh jarak pendek dengan menggunakan start jongkok (Tim Guru Eduka, dalam Suhardi 2015)

Jarak lari sprint adalah 100 meter, 200 meter, 400 meter. Sedangkan menurut. Jarak lari sprint untuk siswa 60 meter(I Bagus Endrawan 2015)

Lari jarak pendek adalah lari yang menempuh arak antara $50 \mathrm{~m}$ sampai dengan jarak $400 \mathrm{~m}$. oleh karena itu kebutuhan utama untuk lari jarak pendek adalah kecepatan (Eddy Purnomo dan Dapan 2011)

Berdasarkan teori-teori yang dijelaskan diatas dapat disimpulkan bahwa sprint adalah lari jarak pendek yang dilakukan dengan kecepatan semaksimal mungkin dalam waktu singkat dengan jarak tempuh 100 meter, 200 meter atau 400 meter.

Permainan tradisional adalah sesuatu yang dilakukan dengan berpegang pada norma atau adat kebiasaan.(Sukriyah 2019) 
Bebentengan merupakan salah satu permainan tradisional yang dulu sangat diminati oleh anak-anak untuk mengisi waktu libur atau hanya sekedar menghilangkan rasa penat. Bebentengan di daerah jawa barat sering kali dikenal sebagai rereboan, sedangkan di daerah lain juga dikenal dengan nama prisprisan, omer, jek-jekan. Bebentengan sendiri berasal dari kata benteng atau pertahanan.

Bebentengan merupakan salah satu permainan tradisional yang dulu sangat diminati oleh anak-anak untuk mengisi waktu libur atau hanya sekedar menghilangkan rasa penat. Bebentengan di daerah jawa barat sering kali dikenal sebagai rereboan, sedangkan di daerah lain juga dikenal dengan nama prisprisan, omer, jek-jekan. Bebentengan sendiri berasal dari kata benteng atau pertahanan.(Ajhun 2010)

Menurut Sri Mulyani bebentengan merupakan permainan tradisional yang memerlukan keterampilan, ketangkasan, kecepatan berlari, serta strategi yang jitu. (Sri Mulyani 2013)

Berdasarkan teori-teori yang dijelaskan diatas dapat disimpulkan bahwa permainan bebentengan adalah salah satu permainan tradisional yang biasa di mainkan oleh anak-anak yang terdiri dari dua regu yang berisikan 4-8 orang, dimana dalam permainan ini dibutuhkan keterampilan dan kecepatan dalam berlari agar dapat merebut benteng lawan

\section{METODE}

Jenis penelitian ini adalah studi literatur atau penelitian kepustakaan. Menurut Mestika Zed penelitian kepustakaan adalah aktifitas yang pasif, statis, dan bias. ${ }^{1}$ yakni usaha memperoleh data dengan cara mendalami, mencermati, menelaah pengetahuan yang ada didalam

\footnotetext{
${ }^{1}$ Dr. Amir Hamzah, MA, Metode Penelitian Kepustakaan, (Sampang: Literasi Nusantara. 2019)h.2
}

kepustakaan (sumber Buku, Jurnal Internasional, Skripsi terdahulu dan Jurnal Nasional).

Penelitian kepustakaan atau kajian litelatur (literature riview, literature research) merupakan penelitian yang mengkaji atau meninjau secara kritis pengetahuan, gagasan, atau temuan yang terdapat di dalam tubuh litelatur berorientasi akademik (academic-oriented literature) serta merumuskan kotribusi teritis dan metodologisnya untuk topik tertentu(Cooper da taylor dalam Mohammad Imam Farisi. 2010)

\section{A. Teknik Pegumpulan Data}

Sumber data adalah segala sesuatu yang dapat memberikan informasi mengenai data. Data yang diperoleh dengan studi literatur (pustaka). Teknik ini disebut juga dengan studi pustaka yaitu cara menelusuri keputakaan yang berisi tentang teori-teori dari karya ilmiah baik yang sudah diterbitkan atau belum diterbitkan berupa hard copy atau sof copy yang ada pada buku-buku (e-books), makalah, journal online. Teknik studi literatur ini bersumber pada buku, laporan penelitian, jurnal ilmiah, dan catatan lain, berusaha mencari sumber-sumber teori yang relevan sesuai dengan tema dan permasalahan penelitian yang telah ditetapkan sehingga penelitian yang dihasilkan sesuai dengan yang diharapkan.

a. Berikut ini adalah deskripsi dari sumber data primer :

1. Penelitian Yang Dilakukan Bambang Hermansah pada tahun 2016 dengan judul penelitian "Pengaruh latihan Permainan Tradisional Bentengan Terhadap Sprint 50 Meter pada Siswa Putra Kelas IV SD 2 Indralaya Utara Ogan Ilir".

2. Penelitian Yang Dilakukan Ahmadi pada tahun 2018 dengan judul 
penelitian "Upaya Meningkatkan Keaktifan Siswa Dalam Pembelajaran Lari Jarak Pendek Melalui Metode Bermain Bentengang Di Kelas V SDN Cilndak Timur 02 Jakarta Selatan".

3. Penelitian Yang Dilakukan Naufal Restu Hidayat, Encep Sudirjo, dan Anin Rukmana pada tahun 2018 dengan judul penelitian "Pengaruh Penerapan Permainan Tradisional Bebentengan Terhadap Motivasi Belajar Siswa Dalam Mengikuti Pembelajaran Lari Sprint."

4. Penelitian Yang Dilakukan Kurnia Pramukanti Asih pada tahun 2015 dengan judul penelitian "Pembelajaran Lari Cepat Melalui Permainan Bentengan Untuk Meningkatkan Partisipasi Dalam Pembelajaran PENJASORKES Pada Siswa Kelas III SD Negeri 2 Randublatung Kabupaten Blora 2013/2014."

5. Penelitian yang dilakukan Sukardi pada tahun 2013 dengan judul penelitian "Upaya Meningkatkan Pembelajaran Lari Sprint 30 meter Melalui Permainan Bentengan Pada siswa Kelas V SD Negeri 1 Seri Menang Kecamatan Pampangan Kabupaten Ogan Komering Ilir Tahun 2016/2017."

b. Berikut ini adalah deskripsi dari sumber data sekunder :

1. Edi Warsidi pada tahun 2010, bukunya yang berjudul "Sejarah dan Teknik Dasar Atletik". Atletik adalah gabungan dari beberapa jenis lolahraga yang secara garis besar dapat dikelompokan menjadi, lari, lempar, dan lompat.

2. Drs. Eddy Purnomo, M.Kes dan Drs. Dapan, M.Kes pada tahun 2011, bukunya berjudul "Dasar-dasar Gerak Atletik". Lari jarak pendek atau sprint adalahlari yang menempuh jarak antara 50 meter samapi dengan jarak 400 meter, oleh karena itu kebutuhan utama untuk lari jarak pendek adalah kecepatan.

3. Rizky Yulita pada tahun 2017, bukunya yang berjudul "Permainan Tradisional Anak Nusantara". Permainan tradisional adalah permainan yang sudah ada sejak zaman dahulu, dimainkan dari generasi ke generasi

4. Ajun Khamandani pada tahun 2010, bukunya yang berjudul "Olahraga Tradisional Indonesia". Benteng atau bebentengan merupakan slah satu jenis olahraga tradisional yang dilakukan oleh dua regu, setiap regu terdiri dari 4 samapi 8 orang.

5. Sri Mulyani pada tahun 2013, bukunya yang berjudul "45 Permainan Tradisional Anak Indonesia”. Benteng atau Bebentengan adalah permainan tradisional yang memerlukan ketangkasan, kecepatan berlari dan strategi yang jitu.

\section{B. Teknik Analisis Data}

Analisis data merupakan upaya mencari dan menata secara sistematis data yang telah terkumpul untuk meningkatkan pemahaman penelitian tentang kasus yang diteliti dan mengkajinya sebagai temuan bagi orang lain. Analisis data yang digunakan dalam penelitian ini teknik analisis data yang digunakan dalam penelitian dengan model dari (Miles dan Huberman) yang terdiri dari tiga tahap, antara lain reduksi data, penyajian data dan penarikan kesimpulan/verifikasi yang dapat dilihat melalui gambar berikut: 


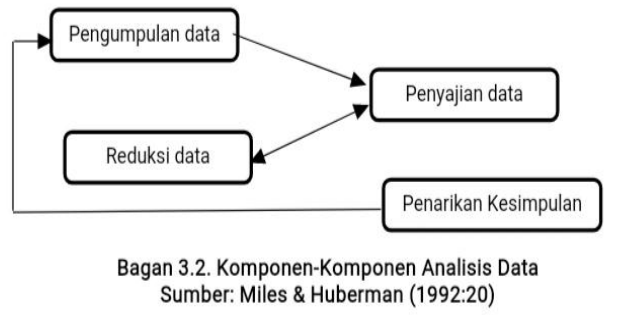

langkah pertama, mereduksi data adalah merangkum, memilih hal-hal yang pokok, memfokuskan pada hal-hal yang dianggap penting, dengan upaya mencari tema dan polanya.

langkah kedua, peneliti menyajikan (display) data. Menurut Miles dan Huberman 1984 dalam Sugiyono (2012:95) yang paling sering digunakan untuk menyajikan data dalam penelitian kualitatif adalah melalui sejumlah teks yang bersifat naratif.

langkah ketiga, peneliti menarik kesimpulan dan verifikasi sebagai jawaban terhadap rumusan masalah yang telah dituangkan sejak awal. kesimpulan merupakan kegiatan yang dilakukan dengan tujuan mencari arti, makna, penjelasan yang dilakukan terhadap data yang telah dianalisis dengan mencari halhal penting. kesimpulan ini merupakan jawaban atas permasalahan yang ingin dikaji sebagaimana dijelaskan pada identifikasi dan perumusan masalah penelitian.( Sugiyono 2016)

\section{Teknik Pengujian Keabsahan Data}

Dalam pengujian keabsahan data, metode literatur menggunakan istilah yang berbeda dengan penelitian kuantitatif. Keabsahan data dilakukan untuk membuktikan apakah penelitian yang dilakukan benar-benar penelitian ilmiah sekaligus untuk menguji data yang diperoleh. Uji keabsahan data dalam penelitian literature berdasarkan triangulasi data.

Menurut William Wiersma dalam Sugiyono (2012:372) Triangulasi dalam pengujian kredibilitas ini diartikan sebagai pengecekan data dari berbagai sumber dengan berbagai cara, dan berbagai waktu.

\section{HASIL DAN PEMBAHASAN}

Penelitan ini dilakukan untuk mengetahui pengaruh permianan tradisional bebentengan terhadap pembelajaran atletik sprint,. Berdasarkan sumber-sumber yang relevan menunjukkan adanya pengaruh permianan tradisional bebentengan terhadap Pembelajaran Atletik Sprint.

Berdasarkan hasil penelitian yang telah dilakukan melalui berbagai sumber yang relevan berupa jurnal maupun buku, maka peneliti menemukan bahwa permainan tradisional bebentengan dapat meningkatkan pemebelajaran atletik sprint. Pernyataan ini didukung oleh berbagai penelitian terdahulu yang memperoleh peningkatan pembelajaran atletik sprint ketika menerapkan permainan tradisional bebentengan dalam kegiatan pembelajaran

Dilakukannya penelitian studi literatur menggunakan beberapa sumber seperti buku-buku yang relevan dengan penelitian yang dilakukan, jurnal-jurnal maupun skripsi terdahulu yang berkaitan. Hal ini sesuai dengan teknik pengujian keabsahan data. Pengujian keabsahan data dilakukan untuk membuktikanapakah penelitian yang dilakukan benar-benar penelitian ilmiah sekaligus untuk menguji data yang diperoleh. Uji keabsahan data dalam penelitian literatur berdasarkan triangulasi data..

Teknik pengujian keabsahan data dalam penelitian kualitatif, salah satunya menggunakan triangulasi. Triangulasi yang digunakan adalah triangulasi sumber. Beberapa sumber yang digunakan yaitu buku-buku yang berkaitan dengan variabel $\mathrm{x}$ dan $\mathrm{y}$ dalam penelitian, jurnaljurnal dan juga skripsi Triangulasi 
sumber difokuskan pada data penelitian yang telah dilakukan sebelumnya.

\section{PENUTUP}

\section{Simpulan}

Berdasarkan data hasil penelitian terdahulu dan melalui studi literatur yang sudah dilakukan dapat diketahui bahwa penggunaan permainan tradisional bebentengan dapat berpengaruh terhadap pembelajaran atletik sprint. Setelah dilakukannya analisis dari berbagai sumber terdahulu yang relevan didapatkan bahwa penggunaan permainan tradisional bebentengan dapat berpengaruh terhadap pembelajaran atletik sprint.

\section{Saran}

Berdasarkan kesimpulan di atas, dapat diusulkan saran yang diharapkan akan bermanfaat bagi penelitian selanjutnya:

1. Bagi Instansi Terkait

Dinas Pendidikan dan Sekolah untuk senantiasa meningkatkan Sumber Daya Manusia, sarana dan prasarana maupun perangkat dalam pembelajaran tentang konsep-konsep pembelajaran yang menarik perhatian siswa.

2. Bagi Siswa

Siswa hendaknya dapat lebih meningkatkan kemampuan melalui latihan, permainan tradisional bebentengan sehingga siswa dapat melakukan pembelajaran atletik sprint dengan kemampuan yang baik untuk mendukung hasil belajarnya.

3. Bagi Peneliti Selanjutnya

a. Bagi peneliti selanjutnya yang tertarik untuk melakukan kajian di bidang yang sama dapat menambah variabel independen maupun dependen yang memiliki kemungkinan pengaruh terhadap keterampilan pembelajaran atletik sprint. b. Peneliti selanjutnya disarankan untuk menambah jumlah sumber referensi sehingga penelitian dapat digeneralisasikan dengan baik.

\section{DAFTAR PUSTAKA}

Diantama, S. (2018). Metode Penelitian

Pendidikan. Bandung: Pustaka

Rahmat

Sugiyono. (2011). Metode Penelitian

Kuantitatif, Kualitatif dan $R \& D$. Bandung: Alfabet

Pandu Kresnapati. (2018). Pengaruh Pola

Latihan Lompat Kijang

Terhadap Hasil Lompat Angkit

Mahasiswa Putra PJKR

UPGRIS. Journal of Sport

Coaching and Physical

Education . h. 8

Yoyo Bahagia, (2010). Metode dan

Pembelajaran Pendidikan

Jasmani, Bandung, UPI Press. h. 2

Eddy Purnomo \& Dapan. (2011). Dasardasar Dasar Atletik. Yogyakarta. Alfamedia

Edi Warsidi. (2010). Sejarah dan teknik dasar Atletik. Bogor. Quadra

Khamdani. (2010). Olahraga Tradisional Indonesia. Singkawang: PT. Maraga Boneo Tarigas

Mulyani, S. (2013). 45 Permainan

Tradisional Anak Indonesia.

Yogyakarta: Langengsari

Publishing

Yulita, R. (2017). Permainan Tradisional

Anak Nusantara. Jakarta:

Badan Pengembangan dan

Pembinaan Bahasa

Edrawan, I Bagus. (2015). Upaya

Meningkatkan Hasil Lari Sprint

60 meter Melalui Permainan

Tradisional Hijau Hitam Pada

Siswa Kelas VII SMPN 38

Palembang. Volume V, Nomor

1. h. 25 
Suhardi dkk. (2016). "Pengaruh

Pendekatan Permainan

Tradisional Terhadap Hasil

Belajar Lari Sprint Pada

Peserta Didik Kelas X”.

Jurnal Program Studi

Penjaskesrek Jurusan Ilmu

Keolahragaan FKIP UNTAN 